\title{
RESEARCH
}

Open Access

\section{Dipeptidyl Peptidase-4 inhibitors use in type II diabetic patients in a tertiary hospital}

Woh Yon Mak, Jivanraj R. Nagarajah, Hannah Abdul Halim, Anitha Ramadas, Zulsairi Mohd Pauzi, Lay Ting Pee and Nirmala Jagan ${ }^{*}$

\begin{abstract}
Background: In Malaysia, for more than a decade, dipeptidyl peptidase-4 inhibitors (DPP-4i) are among the oral antidiabetic medications used as monotherapy or in combination to manage type II diabetes mellitus (T2DM). These medications are known for the efficacy in glycated haemoglobin (HbA1c) reduction and weight neutral effect with minimal hypoglycaemia occurrence. This study aimed to identify the outcomes of DPP-4i use in one of the largest tertiary public hospital in Southeast Asia.

Methods: This is a retrospective cross sectional study conducted in 2016, where stratified sampling method was used. Patients with T2DM treated with available DPP-4i; namely Linagliptin, Saxagliptin, Sitagliptin and Vildagliptin, for at least 3 months were identified from the pharmacy record. Medical records from Physician Clinic in Hospital Kuala Lumpur (HKL) were reviewed. Data on demographic, anthropometric, antidiabetic treatment modalities, laboratory and documented outcomes were collected. Outcomes endpoints which include changes in HbA1c, fasting blood glucose (FBG), and body weight were recorded and analysed. Adverse drug reactions (ADR) documented were also reported.

Results and discussion: A total of one hundred and five patients were recruited. The patients were $49.5 \%$ men $(n=52)$, with a mean age of 57 years, mean $\mathrm{HbA1c}$ of $8.5 \%(69 \mathrm{mmol} / \mathrm{mol})$ and mean BMl of $29.5 \mathrm{~kg} / \mathrm{m}^{2}$. At least $50 \%$ of the patients had T2DM for more than 10 years and more than two third of these patients had both T2DM and hypertension. Thirty nine patients were on Vildagliptin, 32 on Sitagliptin, 26 on Saxagliptin and the remaining on Linagliptin. The most commonly prescribed DPP-4i were Vildagliptin and Sitagliptin. Majority of the patients (90.4\%) were prescribed with Metformin, with $62.8 \%$ of patients on fixed-dose combination, and the remaining on add-on Metformin therapy. Use of DPP-4i as an adjunct was associated with a mean reduction of $0.9 \%$ (9 mmol/ $\mathrm{mol})$ in $\mathrm{HbA1c}(p<0.0001)$ and $1.15 \mathrm{mmol} / \mathrm{L}(19.82 \mathrm{mg} / \mathrm{dL})$ in FBG $(p=0.001)$ without significant weight changes $(p=0.745)$. Sitagliptin had the highest reduction in $\mathrm{HbA1c}(1.66 \%, 19 \mathrm{mmol} / \mathrm{mol} ; p$-value< 0.0001$)$. Twelve ADRs were reported with the highest report on gastrointestinal intolerance $(n=7)$. None of the ADR reported caused any significant harm to the patients.
\end{abstract}

Conclusion: Overall, use of these DPP-4i as an adjunct antidiabetic was associated with reduction in HbA1c. Keywords: Dipeptidyl peptidase 4 inhibitors (DPP4-i), HbA1c, Type II diabetes mellitus (T2DM), Southeast Asia

\footnotetext{
*Correspondence: nimmi.j@gmail.com

Department of Pharmacy, Hospital Kuala Lumpur, Kuala Lumpur, Malaysia

C C The Author(s). 2020 Open Access This article is licensed under a Creative Commons Attribution 4.0 International License, which permits use, sharing, adaptation, distribution and reproduction in any medium or format, as long as you give appropriate credit to the original author(s) and the source, provide a link to the Creative Commons licence, and indicate if changes were made. The images or other third party material in this article are included in the article's Creative Commons licence, unless indicated otherwise in a credit line to the material. If material is not included in the article's Creative Commons licence and your intended use is not permitted by statutory regulation or exceeds the permitted use, you will need to obtain permission directly from the copyright holder. To view a copy of this licence, visit http://creativecommons.org/licenses/by/4.0/. The Creative Commons Public Domain Dedication waiver (http://creativecommons.org/publicdomain/zero/1.0/) applies to the data made available in this article, unless otherwise stated in a credit line to the data.
} 


\section{Background}

\section{Literature review}

Globally, International Diabetes Federation (IDF) [1] reported diabetes prevalence figure of 1 in 11 adults. The figure will increase to 1 in 10 adults by 2040. According to IDF, $12 \%$ of the global health expenditure of approximately 727 billion USD was spent in 2017 in managing patients with diabetes and the figure is expected to increase further in future. Malaysia has one of the highest and most rapidly increasing prevalence of diabetes in the Western Pacific region. The prevalence of diabetes in Malaysia reported in National Health \& Morbidity Survey 2015 (NHMS) [2] had increased from 8.3\% in year 1996 to $17.5 \%$ in year 2015 . In terms of diabetes control, majority of Type 2 Diabetes Mellitus (T2DM) patients in our country failed to achieve their individual glycaemic targets, with only $12.7 \%$ of T2DM patients in tertiary hospitals able to attain their glycaemic targets [3, 4].

Dipeptidyl peptidase-4 inhibitors (DPP-4i) are agents that increase glucagon like peptide-1 (GLP-1) and gastric inhibitory polypeptide (GIP) levels, which inhibit glucagon release leading to increased insulin secretion and thereby reduce blood glucose levels [5]. DDP-4 is a protease involved in GLP-1 inactivation. By inhibiting the enzyme, DPP-4i prolong and enhance the activity of GLP-1. GLP-1 exerts its main effects by stimulating glucose dependent insulin release, slowing gastric emptying, reducing food intake, and decreasing postprandial glucagon excretion $[6,7]$.

DPP-4i have been incorporated into numerous guidelines available for the management of patients with T2DM. American Diabetes Association (ADA) and European Association for the Study of Diabetes (EASD) positioned DPP-4i alongside with sulfonylureas, thiazolidinediones, GLP-1 agonists and insulin, as a second-line add-on to metformin in their general recommendation [8].

According to the National Institute for Health and Clinical Excellence (NICE) guideline on newer agents for blood glucose control in T2DM published in 2009, DPP4i can be considered as a second-line therapy to firstline metformin if there is a significant risk of hypoglycaemia or if a sulfonylurea is contraindicated or not tolerated [9].

According to the Malaysian Clinical Practice Guideline on the Management of T2DM 2015, DPP-4i use is recommended early in patients with HbA1c of $6.5 \%$ (48 $\mathrm{mmol} / \mathrm{mol}$ ) and above as monotherapy or in combination with other antidiabetic agents [10]. DPP-4i that are available in Malaysia include Sitagliptin, Saxagliptin, Vildagliptin, Alogliptin and Linagliptin [11]. Although there are noteworthy pharmacokinetic and pharmacodynamic differences among various types of DPP-4i, there is no clear local or national guideline stating the selection criteria of patients to be started on a certain type of DPP-4i
[12]. Huri $\mathrm{HZ}$ et al. did a retrospective review to analyse the utilization patterns of DPP-4 inhibitors and identified age, concomitant use of beta blockers and aspirin as factors associated with the use of DPP-4i among Malaysia University Malaya Medical Centre (UMMC) patients [13]. However, the study was only limited to Sitagliptin and Vildagliptin.

Currently, DPP-4i are not widely used in Malaysia public healthcare institutions as compared to private healthcare settings [14]. Hospital Kuala Lumpur (HKL) is the largest public tertiary hospital in Southeast Asia with about 11,000 patients actively seeking treatment in its Physician Clinic. HKL physicians have access to four types of DPP-4i, namely Sitagliptin, Saxagliptin, Vildagliptin and Linagliptin. This study aimed to identify the utilization pattern of DPP-4i in HKL and to determine clinical outcomes of patients prescribed with DPP-4i, mainly glycated haemoglobin (HbA1c), fasting blood glucose (FBG) and any occurrence of adverse event.

\section{Methods \\ Study design}

This is a retrospective, cross sectional study involving patients under HKL Physician Clinic follow up. Patients included in this study were T2DM patients aged 18 years and above whom were taking any of the available DPP$4 i$, either as single pill or combination pill, for a minimum of 3 months within year 2011 to 2016. Pregnant patients, patients with psychiatric illness on antipsychotics, end stage renal dysfunction on regular dialysis were excluded from our study.

\section{Study population}

Study subjects were identified through the patient list on DPP-4i in the year 2016 from the pharmacy record using convenient stratified sampling method. The total minimum sample size which gives $80 \%$ study power is 95 , calculated using Epi Info ${ }^{\text {тм }}$ Software version 7.1.5.2 (CDC), assuming expected proportion of patients on DPP-4i of $9.5 \%$ and confidence limit of 5\% [15]. From a total of 385 patients who were on DPP-4i, number of patients who fulfilled the inclusion criteria and recruited was 105 .

\section{Data collection}

Patients' records were retrieved from the physician clinic and data collection was conducted using a structured data collection form (Appendix 1). Data collected include types of DPP-4i commonly prescribed, demographic parameters of patients on DPP-4i, anthropometric, antidiabetic treatment modalities, laboratory data and self-reported outcomes. Changes in HbA1c, fasting blood glucose (FBG) and body weight were recorded and analysed. Adverse drug reactions (ADR) documented were also reported. 
Table 1 Patient's baseline demographic characteristics, $N=105$

\begin{tabular}{|c|c|}
\hline Parameters/characteristics & n (\%) \\
\hline Age (years old) ${ }^{a}$ & $\overline{57.0 \pm 12.1}$ \\
\hline$<60$ & $59(56.2)$ \\
\hline$\geq 60$ & $46(43.8)$ \\
\hline \multicolumn{2}{|l|}{ Gender } \\
\hline Male & $52(49.5)$ \\
\hline Female & $53(50.5)$ \\
\hline \multicolumn{2}{|l|}{ Race } \\
\hline Malay & $53(50.5)$ \\
\hline Chinese & $19(18.0)$ \\
\hline Indian & $32(30.5)$ \\
\hline Others & $1(1.0)$ \\
\hline \multicolumn{2}{|l|}{ Smoking } \\
\hline Yes & $2(1.9)$ \\
\hline No & 93 (88.6) \\
\hline Ex-smoker & $10(9.5)$ \\
\hline \multicolumn{2}{|l|}{ Alcohol consumption } \\
\hline Yes & $1(1.0)$ \\
\hline No & $101(96.1)$ \\
\hline Ex-consumer & $3(2.9)$ \\
\hline Weight $(\mathrm{kg})^{\mathrm{a}}$ & $78.1 \pm 14.5$ \\
\hline Height $(m)^{a}$ & $1.62 \pm 0.08$ \\
\hline BMI $\left(\mathrm{kg} / \mathrm{m}^{2}\right)^{\mathrm{a}, \mathrm{b}}$ & $29.5 \pm 4.6$ \\
\hline < 18.5 (Underweight) & $0(0.0)$ \\
\hline 18.5-22.9 (Normal) & $4(3.8)$ \\
\hline 23.0-27.4 (Overweight) & $38(36.2)$ \\
\hline$\geq 27.5$ (Obese) & $63(60.0)$ \\
\hline \multicolumn{2}{|l|}{ Waist circumference $(\mathrm{cm})^{a}$} \\
\hline Male & $99.7 \pm 11.5$ \\
\hline Female & $94.9 \pm 11.8$ \\
\hline
\end{tabular}

${ }^{a}$ Continuous variable reported as mean \pm SD

${ }^{\mathrm{b}}$ Classification of weight by BMI adapted from Malaysian Clinical Practice

Guideline on the Management of T2DM 2015 [10]

\section{Statistical analysis and data interpretation}

The demographic, medication details and clinical parameters of the study were analysed using descriptive statistics, reported in frequency and percentage. Continuous data were reported as mean \pm standard deviation (SD). Paired T-test was conducted to compare the mean difference of continuous variables pre- and post DPP-4i while Independent $\mathrm{T}$-test and Analysis of variance (ANOVA) were conducted to compare the HbA1c difference between the groups. Post-hoc analysis (Least Significant Differences, LSD) was conducted for significant ANOVA outcomes. Meanwhile, the proportion or categorical variables were compared using Pearson chisquare test. All statistical analyses were conducted using
Table 2 Patient's baseline clinical characteristics, $N=105$

\begin{tabular}{|c|c|}
\hline Parameters/characteristics & $\mathrm{n}(\%)$ \\
\hline Duration of T2DM (years) $^{a}$ & $11.5 \pm 8.5$ \\
\hline$\leq 10$ & $53(50.5)$ \\
\hline $11-20$ & $39(37.1)$ \\
\hline $21-30$ & $8(7.6)$ \\
\hline$>30$ & $5(4.8)$ \\
\hline \multicolumn{2}{|l|}{ Comorbidities } \\
\hline Hypertension & $74(70.5)$ \\
\hline Dyslipidaemia & $50(47.6)$ \\
\hline Ischaemic heart disease & $12(11.4)$ \\
\hline Cerebrovascular accident & $2(1.9)$ \\
\hline Renal impairment & $13(12.4)$ \\
\hline Liver impairment & $9(8.6)$ \\
\hline Heart failure & $5(4.8)$ \\
\hline \multicolumn{2}{|l|}{ Diabetic complications } \\
\hline Neuropathy & $9(8.6)$ \\
\hline Nephropathy & $5(4.8)$ \\
\hline Retinopathy & $12(11.4)$ \\
\hline All of the above & $2(1.9)$ \\
\hline $\mathrm{HbA1c}(\%)^{\mathrm{a}}$ & $8.5 \pm 1.8$ \\
\hline$<6.5$ & $8(7.6)$ \\
\hline $6.5-9.9$ & $76(72.4)$ \\
\hline$\geq 10$ & $21(20.0)$ \\
\hline $\mathrm{FBG}(\mathrm{mmol} / \mathrm{L})^{\mathrm{a}}$ & $9.1 \pm 3.8$ \\
\hline $\operatorname{ALT}(\mu \mathrm{mol} / \mathrm{L})^{\mathrm{a}}$ & $31.0 \pm 0.2$ \\
\hline $\mathrm{TC}(\mathrm{mmol} / \mathrm{L})^{\mathrm{a}}$ & $5.0 \pm 4.0$ \\
\hline $\mathrm{TG}(\mathrm{mmol} / \mathrm{L})^{\mathrm{a}}$ & $1.9 \pm 1.3$ \\
\hline $\operatorname{LDL}(\mathrm{mmol} / \mathrm{L})^{\mathrm{a}}$ & $2.6 \pm 0.9$ \\
\hline $\mathrm{HDL}(\mathrm{mmol} / \mathrm{L})^{\mathrm{a}}$ & $1.2 \pm 0.4$ \\
\hline
\end{tabular}

${ }^{\mathrm{a} C o n t i n u o u s ~ v a r i a b l e ~ r e p o r t e d ~ a s ~ m e a n ~} \pm \mathrm{SD}$

IBM SPSS Statistics version 20.0 where $p$-value of $<0.05$ was considered statistically significant.

\section{Results}

\section{Demographic description}

A total of 105 patients, 52 (49.5\%) men and 53 (50.5\%) women were included in this study. The baseline demographic and clinical characteristics of the patients are described in Table 1 and Table 2, respectively. Mean age of the patients was $57.0 \pm 12.1$ years, almost half $(43.8 \%)$ of them were above 60 years. Two-third of the patients $(60 \%)$ were obese (body mass index $\geq 27.5 \mathrm{~kg} / \mathrm{m}^{2}$ ) and about one-third of them (36\%) were overweight (body mass index $23-27.4 \mathrm{~kg} / \mathrm{m}^{2}$ ), with mean body mass index (BMI) of $29.5 \pm 4.6 \mathrm{~kg} / \mathrm{m}^{2}$.

Mean HbA1c before initiation of DPP- $4 \mathrm{i}$ was $8.5 \pm 1.8 \%$, in which about $72.4 \%$ of the patients had HbA1c ranging 
from 6.6 to $9.9 \%$. Mean baseline FBG was $9.1 \pm 3.8 \mathrm{mmol} /$ $\mathrm{L}(163.8 \pm 68.47 \mathrm{mg} / \mathrm{dL})$. Mean duration of T2DM was $11.5 \pm 8.5$ years and about half of the patients $(52 \%)$ had long-standing T2DM (> 10 years). Hypertension $(\sim 70 \%)$ and dyslipidaemia $(\sim 50 \%)$ were the main comorbidities followed by ischaemic heart disease $(\sim 11 \%)$, renal impairment ( 9\%), liver impairment ( 9\%) and heart failure $(\sim$ $5 \%$ ). Approximately $30 \%$ of the patients had diabetic complications prior to DPP-4i treatment, $12 \%$ retinopathy, $9 \%$ neuropathy and $5 \%$ nephropathy.

\section{Patterns of DPP-4i use}

The patterns of DPP-4i use are described in Table 3. The usage of Vildagliptin, Sitagliptin and Saxagliptin was comparable, with $37 \%(n=39)$ of patients on Vildagliptin, 30.5\% $(n=32)$ of them on Sitagliptin and $24.8 \%$ $(n=26)$ of the patients were on Saxagliptin. The lowest DPP-4i usage was Linagliptin, 7.6\% $(n=8)$. Two third of the patients $(62.8 \%, n=66)$ were on fixed-dose combination (FDC) therapy. Only one patient was on DPP4-i monotherapy of Linagliptin alone. The mean duration of exposure to DPP-4i was 29.7 months. Almost all DPP-4i were administered with Metformin (90.5\%) either in fixed-dose combination (62.9\%) or add on tablets (27.6\%). Other concomitant antidiabetics include insulin (56.2\%), sulphonylurea (26.7\%) and Acarbose (2.9\%).

\section{Outcomes of DPP-4 inhibitors usage}

The outcomes of DPP-4i are described in Tables 4, 5, 6, 7, 8 and 9. Use of DPP-4 inhibitors showed a mean reduction in HbA1c of $0.9 \%$ and reduction in FBG of $1.15 \mathrm{mmol} / \mathrm{L}$ (19.82 $\mathrm{mg} / \mathrm{dL}$ ). The largest reduction in HbA1c were noted among patients on Sitagliptin (mean difference $=1.66 \%, p<0.0001$ ) and Vildagliptin (mean difference $=0.68 \%, p=0.011$ ). The post hoc analysis showed significantly higher reduction in HbA1c in patients on Sitagliptin compared to other DPP-4i, where Sitagliptin versus Vildagliptin (mean difference = $0.99 \%, p=0.010$ ) and Sitagliptin versus Saxagliptin (mean difference $=1.33 \%, p=0.002$ ). Subjects on oral antidiabetics without insulin therapy were analysed as per Table $5 \mathrm{~b}$. There was significant change in HbAlc pre and post DPP-4i use even without concurrent insulin therapy $(p<0.0001)$. Larger reduction in HbA1c were observed among those on Sitagliptin and Vildagliptin and there was no significant difference in
Table 3 Patterns of DPP-4i use, $N=105$

\begin{tabular}{|c|c|}
\hline Parameters/characteristics & n (\%) \\
\hline \multicolumn{2}{|l|}{ Types of DPP-4i } \\
\hline Vildagliptin & $39(37.1)$ \\
\hline Sitagliptin & $32(30.5)$ \\
\hline Saxagliptin & $26(24.8)$ \\
\hline Linagliptin & $8(7.6)$ \\
\hline Duration of use (months) ${ }^{a}$ & $29.7 \pm 19.8$ \\
\hline$<24$ & $46(43.8)$ \\
\hline$\geq 24$ & $59(56.2)$ \\
\hline \multicolumn{2}{|c|}{ Fixed-dose combination (FDC) tablets } \\
\hline Vildagliptin/Metformin & $27(25.7)$ \\
\hline Sitagliptin/Metformin & $21(20.0)$ \\
\hline Saxagliptin/Metformin & $18(17.1)$ \\
\hline \multicolumn{2}{|l|}{ Metformin } \\
\hline FDC & $66(62.9)$ \\
\hline Add on & $29(27.6)$ \\
\hline Total & $95(90.5)$ \\
\hline \multicolumn{2}{|c|}{ Other concurrent antidiabetics } \\
\hline Insulin & $59(56.2)$ \\
\hline Gliclazide IR/MR & $27(25.7)$ \\
\hline Glibenclamide & $1(1.0)$ \\
\hline Acarbose & $3(2.9)$ \\
\hline None & $28(26.7)$ \\
\hline \multicolumn{2}{|l|}{ Types of insulin therapy } \\
\hline Basal bolus & $28(26.7)$ \\
\hline Premixed & $15(14.3)$ \\
\hline Bolus only & $15(14.3)$ \\
\hline Basal only & $1(1.0)$ \\
\hline \multicolumn{2}{|l|}{ Adherence } \\
\hline Good & $58(55.2)$ \\
\hline Poor & $13(12.4)$ \\
\hline Not documented & $34(32.4)$ \\
\hline
\end{tabular}

Table 4 Outcomes of DPP-4i use, N = 105

\begin{tabular}{lllll}
\hline Parameters & Pre DPP-4i use & Post DPP-4i use & Mean difference $(95 \%$ Cl) & $p$ value \\
\hline HbA1c (\%) & $8.5 \pm 1.8$ & $7.6 \pm 1.7$ & $-0.90(-1.22,-0.58)$ & $<0.0001^{*}$ \\
FBG $(\mathrm{mmol} / \mathrm{L})$ & $9.2 \pm 3.8$ & $8.0 \pm 3.2$ & $-1.15(-1.80,-0.51)$ & $0.001^{*}$ \\
Weight $(\mathrm{kg})$ & $78.1 \pm 14.5$ & $78.1 \pm 14.4$ & $0.08(-0.41,0.57)$ & 0.745 \\
BMI $\left(\mathrm{kg} / \mathrm{m}^{2}\right)$ & $29.5 \pm 4.6$ & $30.0 \pm 7.0$ & $0.50(-0.51,1.51)$ & 0.332 \\
\hline
\end{tabular}

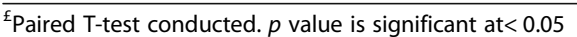

Values reported as mean \pm SD. 
Table $5 \mathrm{HbA} 1 \mathrm{c}$ pattern, $N=105$

\begin{tabular}{lll}
\hline $\mathrm{HbA1c}$ & $\begin{array}{l}\text { Pre DPP-4i use } \\
\mathrm{n}(\%)\end{array}$ & $\begin{array}{l}\text { Post DPP-4i use } \\
\mathrm{n}(\%)\end{array}$ \\
\hline $\mathbf{6 6 . 5 \%}$ & $8(7.6)$ & $21(20.0)$ \\
$\mathbf{6 . 5 - 9 . 9 \%}$ & $76(72.4)$ & $70(66.7)$ \\
$\mathbf{1 0 \%}$ & $21(20.0)$ & $14(13.3)$ \\
\hline
\end{tabular}

$\mathrm{X}^{2}=52.56, \mathrm{df}=4, p$ value $<0.0001$ (significant)

the HbA1c drop between the types of DPP-4i used in patients who were not on insulin.

A total of 12 cases of adverse drug reactions (ADR) were reported among the study population (12\%), six reports from Saxagliptin, three from Sitagliptin and another three reports from Vildagliptin. Most common ADR was gastrointestinal intolerance $(6.7 \%, n=7)$, followed by dizziness $(3 \%, n=3)$, hypoglycaemia ( $1 \%$, $n=1)$ and leg oedema $(1 \%, n=1)$.

Seven patients experienced gastrointestinal intolerance, three patients were on Saxagliptin/Metformin, two patients on Vildagliptin/Metformin and another two patients were on Sitagliptin/Metformin. One of them was switched to Linagliptin monotherapy as patient developed gastrointestinal intolerance due to Metformin. One patient on Vildagliptin/Metformin and two patients on Sitagliptin/Metformin were switched to Saxagliptin single pill without Metformin. The remaining three patients had their current FDC of DPP-4i continued.

One patient on Vildagliptin/Metformin complained of dizziness and was switched to Saxagliptin/Metformin. Meanwhile, another two cases of dizziness reported by patients on Saxagliptin/Metformin were continued on the same therapy. One case of bilateral leg oedema was reported with Sitagliptin/Metformin and was switched to Saxagliptin/Metformin. Only one case of hypoglycaemia was reported but that particular patient was on Saxagliptin/Metformin, Gliclazide and basal insulin concurrently.

No significant weight change was observed pre and post DPP4i use (mean difference $+0.08 \mathrm{~kg}$ ).

\section{Discussion}

Malaysian Clinical Practice Guideline on the Management of T2DM has included DPP-4i as an alternative or addition to Metformin in managing T2DM patients with HbA1c of 6.5 to $10 \%$ [10]. Majority of the patients in

Table $6 \mathrm{HbA} 1 \mathrm{c}$ pattern, $N=47$ (patients without insulin)

\begin{tabular}{lll}
\hline HbA1c & $\begin{array}{l}\text { Pre DPP-4i use } \\
\mathrm{n}(\%)\end{array}$ & $\begin{array}{l}\text { Post DPP-4i use } \\
\mathrm{n}(\%)\end{array}$ \\
\hline $\mathbf{< 6 . 5 \%}$ & $5(10.6))$ & $14(29.8)$ \\
$\mathbf{6 . 5 - 9 . 9 \%}$ & $37(78.8)$ & $32(68.1)$ \\
$\mathbf{2 0 \%}$ & $5(10.6)$ & $1(2.1)$ \\
\hline
\end{tabular}

$\mathrm{X}^{2}=43.57, \mathrm{df}=2, p$ value $<0.0001$ (significant). this study had HbA1c in the range of 6.6 to $9.9 \%$ before initiation of DPP-4i.

DPP-4i can be started regardless of how long patient have had diabetes as its efficacy is not influenced by the duration of T2DM [16-21]. Time of starting DPP-4i to the duration of diabetes is less than 10 years in half of the patients studied. The average age of patients on DPP4i in this study was 57 years with two third of the patients being either overweight (BMI $23-27.4 \mathrm{~kg} / \mathrm{m}^{2}$ ) or obese (BMI $\geq 27.5 \mathrm{~kg} / \mathrm{m}^{2}$ ). These findings are similar to the data published in the National Diabetes Registry Report [22] on Malaysian T2DM population, where mean age was 59.7 years and average BMI was $27.4 \mathrm{~kg} / \mathrm{m}^{2}$. In this study, number of T2DM patients was the highest among Malays followed by Indians and Chinese, which again coincides with the data reported in Malaysia $\mathrm{Na}$ tional Diabetes Registry Report [22].

Hypertension was the most common comorbidity in our patient population, followed by dyslipidemia and ischaemic heart disease. Huri HZ et al. [13] reported similar results in their study population for hypertension and dyslipidemia while Mafauzy [23] found that hypertension was the most prevalent comorbid condition among diabetic patients from 49 private clinics in Malaysia.

All available DPP-4i were prescribed equally except Linagliptin, which was the least prescribed. FDC pill of DPP-4i with Metformin were preferred compared to single pill DPP4-I as FDC pills can reduce patients' overall pill burden. DPP-4i are preferred over the traditional choice of sulphonylurea as second line treatment as DPP-4i have low risk of causing hypoglycaemia especially in elderly patients (46\% of the study population) [10]. Patients who received FDC pill of DPP4-i and Metformin had significantly larger HbA1c reduction compared to the group receiving non FDC. This is probably due to better compliance towards FDC attributed to the lesser pill burden.

This study had shown significant reduction in HbA1c and FBG post DPP-4i as an adjunct therapy, where there was a drop in HbA1c to below 6.5\% post DPP-4i therapy in about a quarter of the study population. On the contrary, studies in other countries to date mainly assessed effectiveness of DPP4-i as monotherapy alone or DPP4-i individual agent compared to other single oral antidiabetic as monotherapy, which resulted an average HbA1c reduction of 0.5 to $0.8 \%$ [16-21].

Present study showed that both Sitagliptin and Vildagliptin use notably had larger HbA1c reduction post therapy. The largest HbA1c drop was observed in the group of patients using Sitagliptin. This outcome might be due to the predominantly higher baseline HbA1c in patients on Sitagliptin. Moreover, almost a quarter of the study population had baseline HbA1c of $10 \%$ and above, which is considerably higher compared to the 
Table 7 Change in HbA1c with DPP-4i use, N = 105

\begin{tabular}{|c|c|c|c|c|c|}
\hline & Pre DPP-4i use & Post DPP-4i use & Mean difference $\pm 95 \% \mathrm{Cl}$ & $P$ value ${ }^{f}$ & $\boldsymbol{P}$ value $^{*}$ \\
\hline \multicolumn{6}{|l|}{ Age (years old) } \\
\hline$<60$ & $8.7 \pm 2.0$ & $7.8 \pm 1.7$ & $0.89(0.44,1.34)$ & $<0.0001^{*}$ & \multirow[t]{2}{*}{0.963} \\
\hline$\geq 60$ & $8.3 \pm 1.5$ & $7.4 \pm 1.6$ & $0.91(0.45,1.36)$ & $<0.0001^{*}$ & \\
\hline \multicolumn{6}{|l|}{ Type of DPP-4i } \\
\hline Vildagliptin & $8.1 \pm 1.5$ & $7.4 \pm 1.6$ & $0.68(0.21,1.14)$ & $0.006^{*}$ & \multirow[t]{4}{*}{$0.011^{\zeta}$} \\
\hline Sitagliptin & $9.2 \pm 2.2$ & $7.5 \pm 1.8$ & $1.66(0.95,2.37)$ & $<0.0001^{*}$ & \\
\hline Saxagliptin & $8.4 \pm 1.4$ & $8.0 \pm 1.5$ & $0.33(-0.03,0.67)$ & 0.052 & \\
\hline Linagliptin & $8.8 \pm 2.1$ & $8.1 \pm 2.1$ & $0.76(-1.12,2.64)$ & 0.370 & \\
\hline \multicolumn{6}{|l|}{ Gender } \\
\hline Male & $8.5 \pm 1.8$ & $7.4 \pm 1.5$ & $1.13(0.59,1.66)$ & $<0.0001^{*}$ & \multirow[t]{2}{*}{0.162} \\
\hline Female & $8.6 \pm 1.8$ & $7.9 \pm 1.8$ & $0.68(0.31,1.04)$ & $<0.0001^{*}$ & \\
\hline \multicolumn{6}{|l|}{ Therapy } \\
\hline FDC & $8.6 \pm 1.8$ & $7.6 \pm 1.7$ & $0.99(0.60,1.38)$ & $<0.0001^{*}$ & \multirow[t]{2}{*}{0.455} \\
\hline Single pill & $8.5 \pm 1.8$ & $7.8 \pm 1.7$ & $0.74(0.18,1.30)$ & $0.011^{*}$ & \\
\hline \multicolumn{6}{|l|}{ Insulin } \\
\hline Yes & $9.0 \pm 2.0$ & $8.2 \pm 1.9$ & $0.81(0.37,1.25)$ & $<0.0001^{*}$ & \multirow[t]{2}{*}{0.554} \\
\hline No & $8.0 \pm 1.5$ & $7.0 \pm 1.1$ & $1.00(0.53,1.48)$ & $<0.0001^{*}$ & \\
\hline \multicolumn{6}{|l|}{ Sulphonylurea } \\
\hline Yes & $8.2 \pm 1.1$ & $7.2 \pm 1.1$ & $0.96(0.36,1.56)$ & $0.003^{*}$ & \multirow[t]{2}{*}{0.824} \\
\hline No & $8.7 \pm 2.0$ & $7.8 \pm 1.8$ & $0.88(0.49,1.26)$ & $<0.0001^{*}$ & \\
\hline
\end{tabular}

${ }^{\text {E}}$ Paired T-test conducted to compare pre and post DPP-4i HbA1c

${ }^{*}$ Independent T-test and ANOVA conducted to compare the HbA1c difference between the groups

'Post-hoc analysis (LSD) conducted for types of DPP-4i

Values reported as mean \pm SD

${ }^{*} p$ value is significant at $<0.05$

baseline HbA1c set as recruitment criteria in other similar studies $(7.5-8.5 \%)$ [16-21]. We found similar reduction in HbA1c among patients on DPP4-i even without concurrent insulin. A separate analysis is necessary to eliminate the possible confounding effect by concurrent insulin therapy as insulin is reported to be able to reduce HbA1c of more than $1.5 \%$ [10].

Table 8 Change in HbA1c with DPP-4i use, $N=47$ (patients without insulin)

\begin{tabular}{|c|c|c|c|c|c|c|}
\hline $\begin{array}{l}\text { Type of } \\
\text { DPP-4i }\end{array}$ & n (\%) & $\begin{array}{l}\text { Pre } \\
\text { DPP-4i } \\
\text { use }\end{array}$ & $\begin{array}{l}\text { Post } \\
\text { DPP-4i } \\
\text { use }\end{array}$ & $\begin{array}{l}\text { Mean } \\
\text { difference } \\
(95 \% \mathrm{Cl})\end{array}$ & $\begin{array}{l}P \\
\text { value }^{\mathbf{E}}\end{array}$ & $\begin{array}{l}P \\
\text { value }^{*}\end{array}$ \\
\hline Vildagliptin & $\begin{array}{l}20 \\
(42.6)\end{array}$ & $7.7 \pm 0.9$ & $6.7 \pm 0.8$ & $\begin{array}{l}1.03(0.37 \\
1.68)\end{array}$ & $0.004^{*}$ & $0.104^{\xi}$ \\
\hline Sitagliptin & $\begin{array}{l}13 \\
(27.7)\end{array}$ & $8.8 \pm 2.1$ & $7.1 \pm 1.4$ & $\begin{array}{l}1.69(0.25 \\
3.13)\end{array}$ & $0.025^{*}$ & \\
\hline Saxagliptin & $\begin{array}{l}13 \\
(27.7)\end{array}$ & $7.8 \pm 1.3$ & $7.4 \pm 1.1$ & $\begin{array}{l}0.32(-0.06 \\
0.71)\end{array}$ & 0.094 & \\
\hline Linagliptin & $\begin{array}{l}1 \\
(2.1)\end{array}$ & & & & & \\
\hline
\end{tabular}

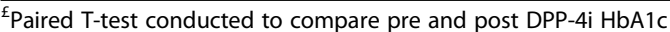
${ }^{*}$ ANOVA conducted to compare the HbA1c difference between the groups Values reported as mean \pm SD

${ }^{*} p$ value is significant at $<0.05$

Linagliptin omitted from analysis as $n=1$

\section{Limitations}

Several limitations were identified in this study. HbA1c outcomes were obtained at varied duration of DPP4-i use as $\mathrm{HbA1c}$ investigation was performed at different

Table 9 ADR related to DPP-4i use, $N=105$

\begin{tabular}{lll}
\hline Parameters/characteristics & & $\mathrm{n}(\%)$ \\
\hline ADR occurrence & Saxagliptin & 6 \\
& Sitagliptin & 3 \\
& Linagliptin & 0 \\
& Vildagliptin & 3 \\
Types of ADR & Gastrointestinal intolerance & $7(6.7)$ \\
& Dizziness & $3(2.9)$ \\
& Hypoglycaemia & $1(1.0)$ \\
Action taken when ADR occurs & Leg oedema & $1(1.0)$ \\
& Change to different DPP-4i & $6(50.0)$ \\
& Continue the same DPP-4i & $5(42.7)$ \\
& Dose reduction & $1(8.3)$ \\
& Discontinuation of DPP-4i & $0(0.0)$ \\
& Saxagliptin/Metformin & $4(50.0)$ \\
& Saxagliptin & $1(33.3)$ \\
& Linagliptin & $1(16.7)$ \\
\hline
\end{tabular}


time period from the time of DPP4-i initiation for each patient. In addition, more than one third of the patients' medication adherence were not assessed and documented in this study. Thus the impact of medication adherence towards treatment outcome cannot be determined.

\section{Conclusion}

In conclusion, this study showed that use of DPP-4i as an adjunct was associated with a significant reduction in patients' HbA1c and FBG without significant weight change. Sitagliptin showed the greatest $\mathrm{HbA1c}$ reduction. DPP-4i were well tolerated with no significant reported adverse drug reaction.

\section{Future direction}

This study can be extrapolated prospectively to investigate the factors associated with utilization of DPP4-i. Furthermore, results can be refined by categorizing patients according to concomitant antidiabetic agents used and whether dosages of each agent are optimized.

\section{Appendix}

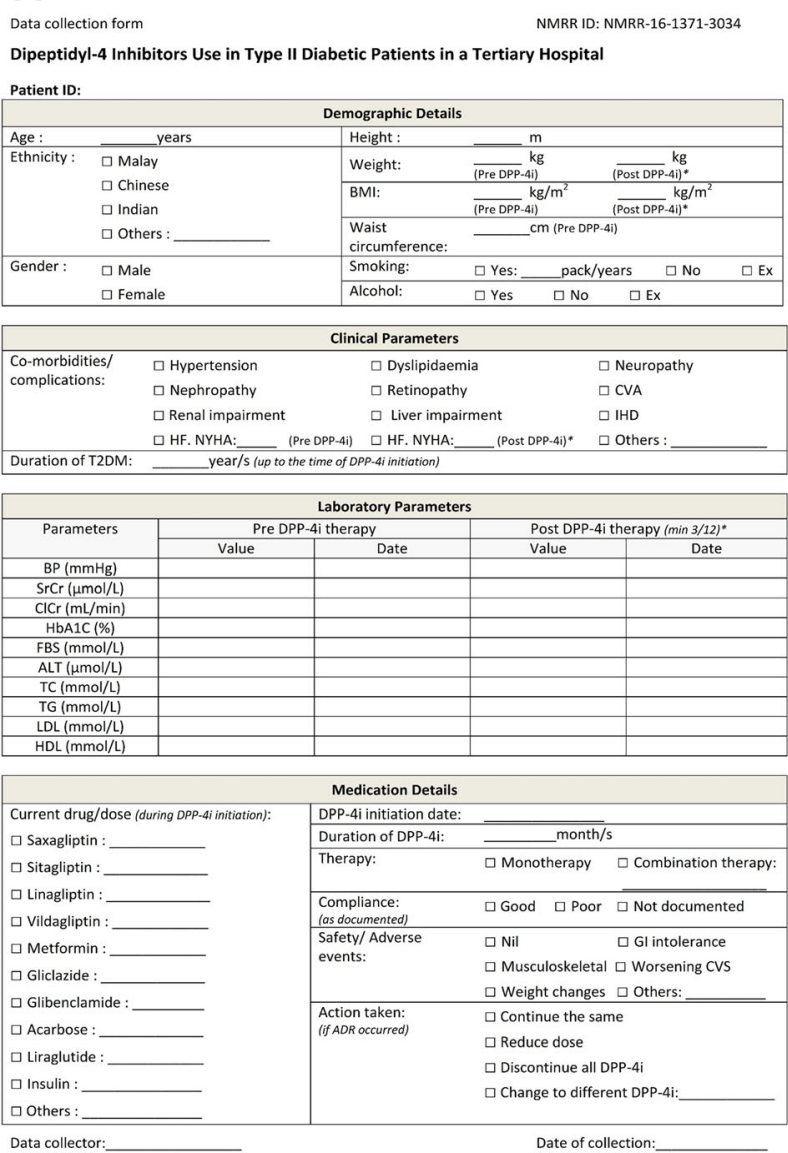

Abbreviations

ADR: Adverse drug reactions; ALT: Alanine transaminase; ANOVA: Analysis of variance; BMI : Body mass index; DPP-4i: Dipeptidyl peptidase-4 inhibitors;
FBG: Fasting blood glucose; FDC: Fixed-dose combination; GLP-1: Glucagon like peptide-1; HbA1c: Glycated haemoglobin; HDL: High-density lipoprotein; IR: Immediate release; LDL: Low-density lipoprotein; LSD: Least Significant Differences; MR: Modified release; SD: Standard deviation; T2DM: Type II diabetes mellitus; TC: Total cholesterol; TG: Triglyceride

\section{Acknowledgements}

Not applicable

\section{Authors' contributions}

All authors contributed in collecting and analysing data for the study. All authors were also involved in the write-up of the manuscript. The authors read and approved the final manuscript.

\section{Funding}

This study was not funded by any party.

\section{Availability of data and materials}

All data generated or analysed during this study were included in this article.

Ethics approval and consent to participate

Approval was obtained from the Ministry of Health Medical Research Ethics Committee (MREC) and the director of the hospital to conduct this study. National Medical Research Register (NMRR) ID: NMRR-16-1371-3034

\section{Consent for publication}

Not applicable.

\section{Competing interests}

The authors declare that they have no competing interests.

Published online: 18 June 2020

References

1. International Diabetes Federation. IDF diabetes atlas. 6th ed. Belgium: International Diabetes Federation; 2013. http://www.idf.org/e-library/ epidemiology-research/diabetes-atlas/19-atlas-6th-edition.html. Assessed 10 Jan 2017.

2. Institute for Public Health (IPH). National Health and morbidity survey 2015 (NHMS 2015). Vol. II: non-communicable diseases, Risk Factors \& Other Health Problems. Kuala Lumpur: Ministry of Health Malaysia; 2015. http:// www.moh.gov.my/moh/resources/nhmsreport2015vol2.pdf. Assessed 10 Jan 2017

3. Feisul I, Soraya A. National Diabetes Registry 2009-2012. Putrajaya: NonCommunicable Disease Section, Disease Control Division, Department of Public Health, Ministry of Health Malaysia; 2013. http://www.moh.gov.my/ moh/resources/Penerbitan/Rujukan/NCD/Diabetes/National_Diabetes_ Registry_Report_Vol_1_2009_2012.pdf. Assessed 11 Jan 2017.

4. Mafauzy M, Zanariah H, Nazeri A, Chan SP. DiabCare 2013: a cross-sectional study of hospital based diabetes care delivery and prevention of diabetes related complications in Malaysia. Med J Malays. 2016:71(4):177-85.

5. Hariprasath K, Umamaheswari P, Wicket SD. Hormone based therapy in type 2 diabetes mellitus. Asian J Pharm Clin Res. 2013;6:1-5.

6. Thornberry NA, Gallwitz B. Mechanism of action of inhibitors of dipeptidylpeptidase-4 (DPP-4). Best Pract Res Clin Endocrinol Metab. 2009;23(4):479-86.

7. Vella A. Mechanism of action of DPP-4 inhibitors - new insights. J Clin Endocrinol Metab. 2012;97(8):2626-8.

8. Inzucchi SE, Bergenstal RM, Buse JB, et al. Management of hyperglycemia in type 2 diabetes: a patient-centered approach: position statement of the American Diabetes Association (ADA) and the European Association for the Study of diabetes (EASD). Diabetes Care. 2012;35:1364-79.

9. Centre for Clinical Practice at NICE. Type 2 diabetes: newer agents for blood glucose control in type 2 diabetes. (NICE clinical guidelines, no. 87). London: National Institute for Health and Clinical Excellence; 2009. https://www.ncbi. nlm.nih.gov/books/NBK61847/. Assessed 10 Jan 2017.

10. Malaysian Endocrine and Metabolism Society. Malaysian clinical practice guideline for Management of Type 2 diabetes mellitus. 5th ed. Malaysia: Academy of Medicine of Malaysia, Ministry of Health; 2015. http://www. moh.gov.my/moh/resources/Penerbitan/CPG/Endocrine/3a.pdf. Assessed 15 Jan 2017. 
11. Ministry of Health Malaysia. Drug formulary. Malaysia: Ministry of Health; 2017. https:/www.pharmacy.gov.my/v2/en/documents/ministry-healthmedicines-formulary-mohmf.html. Assessed 20 Jan 2017.

12. Duez H, Cariou B, Staels B. DPP-4 inhibitors in the treatment of type 2 diabetes. Biochem Pharmacol. 2012;83:7.

13. Huri HZ, Selamat NF, Vethakkan SR. Factors associated with utilization of dipeptidyl-4 inhibitors in patients with type 2 diabetes mellitus: a crosssectional retrospective study. Int J Endocrinol. 2014;2014:367564.

14. Pharmaceutical Services Division and the Clinical Research Centre. Malaysian statistics on medicine 2011-2014. Malaysia: Pharmaceutical services Programme, Ministry of Health; 2017. https://www.pharmacy.gov.my/v2/ sites/default/files/document-upload/malaysian-statistics-medicines-2011-2 014.pdf. Assessed 1 Dec 2017.

15. Khalam A, Dilip C, Shinu C. Drug use evaluation of diabetes mellitus in hospitalized patients of a tertiary care referral hospital. J Basic Clin Physiol Pharmacol. 2012;23(4):173-7.

16. Raz I, Hanefeld M, Xu L, et al. Efficacy and safety of the dipeptidyl peptidase-4 inhibitor sitagliptin as monotherapy in patients with type 2 diabetes mellitus. Diabetologia. 2006:49(11):2564-71.

17. Nonaka K, Kakikawa T, Sato A, et al. Efficacy and safety of sitagliptin monotherapy in Japanese patients with type 2 diabetes. Diabetes Res Clin Pract. 2008:79(2):291-8.

18. Rosenstock J, Wilson C, Fleck P. Alogliptin versus glipizide monotherapy in elderly type 2 diabetes mellitus patients with mild hyperglycaemia: a prospective, double-blind, randomized, 1-year study. Diabetes Obes Metab. 2013;15(10):906-14.

19. Rosenstock J, Aguilar-Salinas C, Klein E, et al. Effect of saxagliptin monotherapy in treatment-naive patients with type 2 diabetes. Curr Med Res Opin. 2009;25(10):2401-11.

20. Barnett AH, Patel $\mathrm{S}$, Harper $\mathrm{R}$, et al. Linagliptin monotherapy in type 2 diabetes patients for whom metformin is inappropriate: an 18-week randomized, double-blind, placebo-controlled phase III trial with a 34-week active-controlled extension. Diabetes Obes Metab. 2012;14(12):1145-54.

21. Rosenstock J, Baron MA, Dejager S, Mills D, Schweizer A. Comparison of vildagliptin and rosiglitazone monotherapy in patients with type 2 diabetes: a 24-week, double-blind, randomized trial. Diabetes Care. 2007;30(2):217-23.

22. Chan SP. Diabetes care model in Malaysia. J ASEAN Federation Endocr Soc. 2015;30(2):100

23. Mafauzy M. Diabetes control and complications in private primary healthcare in Malaysia. Med J Malays. 2005;60(2):212-7.

\section{Publisher's Note}

Springer Nature remains neutral with regard to jurisdictional claims in published maps and institutional affiliations.

Ready to submit your research? Choose BMC and benefit from:

- fast, convenient online submission

- thorough peer review by experienced researchers in your field

- rapid publication on acceptance

- support for research data, including large and complex data types

- gold Open Access which fosters wider collaboration and increased citations

- maximum visibility for your research: over $100 \mathrm{M}$ website views per year

At $\mathrm{BMC}$, research is always in progress.

Learn more biomedcentral.com/submissions 